\title{
NUMERICAL SIMULATION OF FLUID FLOW IN A CUBIC CAVITY WITH A FOUR-FINNED DISSIPATOR PLACED ON THE BOTTOM SURFACE
}

\author{
R. F. Brito ${ }^{a}$, \\ H. S. Alencar ${ }^{b}$, \\ L. O. Rodrigues ${ }^{\mathrm{c}}$, \\ G. J. Menon ${ }^{\mathrm{c}}$, \\ and M. A. R. Nascimento \\ ${ }^{\mathrm{a}, \mathrm{c}}$ Universidade Federal de Itajubá \\ Departamento de Engenharia Mecânica \\ Bairro Pinheirinho \\ CP. 50, Itajubá, MG, CEP: 37500-903, Brasil \\ rogbrito@unifei.edu.br \\ lucilener@unifei.edu.br \\ genesio@unifei.edu.br \\ marcoantonio@unifei.edu.br \\ ${ }^{\mathrm{b}}$ Alstom Equipamentos do Brasil \\ Centro de Tecnologia \\ Av. Charles Sheineider, $\mathrm{s} / \mathrm{n}^{\circ}$ \\ Bairro Barranco \\ Taubaté, SP, CEP: 12400-040, Brasil \\ haarley@terra.com.br
}

\section{ABSTRACT}

Heat transfer by laminar natural convection in confined spaces is of great interest in the engineering field. The flow that occurs in a cavity is an important physical phenomenon that must be investigated, as it can be applied to projects of electronic components of electrical circuits with heat dissipators. The objective of the numerical model consists of evaluating the amount of heat transferred by the fins and also visualizing the velocity field and the isothermal lines in the fluid (air) and solid (aluminum) domains. The surface of the electronic component is kept at a high uniform temperature. The vertical surfaces are uniformly kept at low temperatures. The inferior horizontal surface around the electronic component and the superior horizontal surface are considered adiabatic. Four fins with rectangular crosssections are placed on the inferior surface of the electronic component. Solutions for low values of Rayleigh are obtained by keeping the Prandtl number equal to 0.70. The Computational Fluid Dynamics (CFD) is used. Hence, the Finite Volume Method (FVM) with Eulerian scheme is applied to solve the conservation equations for the unsteady state. It is assembled a $3 \mathrm{D}$ model with width wide enough to eliminate the wall effect in the flow and then enabling one to compare the results with $2 \mathrm{D}$ cases from literature. The present work shows that not only the increase of the Rayleigh number, but also the presence of the fins augments the heat transfer.

Keywords: Natural convection, fins, cavities, heat dissipators, CFD

\section{NOMENCLATURE}

A area, $\mathrm{m}^{2}$

$\mathrm{a}, \mathrm{b}$ dimensions of the surface at an uniform high temperature, $\mathrm{m}$

CFD computational fluid dynamics

$c_{p} \quad$ fluid specific heat at constant pressure, $\mathrm{J} /(\mathrm{kg} . \mathrm{K})$

FVM finite volume method

$\mathrm{g} \quad$ acceleration of gravity, $\mathrm{m} / \mathrm{s}^{2}$

Gr Grashof number

$\mathrm{H} \quad$ geometry height, $\mathrm{m}$

$\mathrm{h}$ heat transfer coefficient, $\mathrm{W} /\left(\mathrm{m}^{2} \mathrm{~K}\right)$

$\mathrm{k}$ thermal conductivity, $\mathrm{W} /(\mathrm{m} . \mathrm{K})$

$\mathrm{L} \quad$ geometry length, $\mathrm{m}$

$\mathrm{n} \quad$ normal direction

$\mathrm{N}$ normal direction

$\mathrm{Nu} \quad$ average Nusselt number

$\mathrm{Nu}_{\mathrm{L}} \quad$ local Nusselt number

$\mathrm{P} \quad$ dimensionless pressure

$\mathrm{p} \quad$ pressure, $\mathrm{N} / \mathrm{m}^{2}$

Pr Prandtl number

Q heat flux rate, $\mathrm{W}$

q heat flux, $\mathrm{W} / \mathrm{m}^{2}$

$\mathrm{Q}_{\mathrm{fi}}$ heat flux rate delivered, $\mathrm{W}$
$\mathrm{Q}_{\mathrm{w}} \quad$ heat flux rate received, $\mathrm{W}$

Ra Rayleigh number

RAM random access memory

RMS root mean square

$\mathrm{S}_{1}, \ldots, \mathrm{S}_{7}$ surfaces of the geometry

SIMPLE semi implicit method for pressure linked equation

$\mathrm{T}$ temperature, $\mathrm{K}$

t time, $\mathrm{s}$

$\mathrm{U}, \mathrm{V}, \mathrm{W}$ dimensionless velocity components

$\mathrm{u}, \mathrm{v}, \mathrm{w} \quad$ velocity components, $\mathrm{m} / \mathrm{s}$

$\mathrm{x}, \mathrm{y}, \mathrm{Z} \quad$ cartesian coordinates, $\mathrm{m}$

$\mathrm{X}, \mathrm{Y}, \mathrm{Z}$ dimensionless cartesian coordinates

\section{Greek symbols}

$\begin{array}{ll}\rho & \text { density, } \mathrm{kg} / \mathrm{m}^{3} \\ \theta & \text { dimensionless temperature } \\ \tau & \text { dimensionless time } \\ \nu & \text { kinematic viscosity, } \mathrm{m}^{2} / \mathrm{s} \\ \delta & \text { lenght, } \mathrm{m} \\ \alpha & \text { thermal diffusivity, } \mathrm{m}^{2} / \mathrm{s} \\ \mu & \text { dynamic viscosity, } \mathrm{N} \mathrm{s} / \mathrm{m}^{2} \\ \beta & \text { volumetric coefficient of thermal } \\ & \text { expansion, } \mathrm{K}^{-1}\end{array}$


$\Omega$

computational domain

\section{Subscripts}

$\begin{array}{ll}\text { 0 } & \text { average value } \\ \text { c } & \text { cold or contact } \\ \text { f } & \text { fluid } \\ \text { fi } & \text { fin } \\ \text { h } & \text { hot } \\ \text { L } & \text { local } \\ \text { s } & \text { solid } \\ \text { W } & \text { wall }\end{array}$

\section{INTRODUCTION}

During the last four decades, significant attention was given to the study of natural convection in enclosures subjected to heating and cooling using four-finned dissipators placed on a heated base. This was due to the occurrence of natural convection in a wide range of application areas that include nuclear reactor design, post-accident heat removal in nuclear reactors, geophysics and underground storage of nuclear waste, energy storage systems and others. Natural convection heat transfer in enclosures containing heat generating fluids with different geometrical parameters and boundary conditions has been extensively considered in the open literature.

Several electronic equipments have been designed to be closed rectangular boxes with small openings on the bottom surface to allow natural ventilation. Components of electronic equipment are usually placed on the bottom surface of the cavity. They always dissipate heat at a constant temperature even on the standby mode. Although many works deal with laminar natural convective flow, some still consider a partially heated base.

In the case of natural convection in a twodimensional domain, many works have been experimentally and numerically developed.

Dong and Li (2004) carried out a study of natural convection inside a cavity which is crossed by a horizontal cylinder using the Stream function Method and the Boussinesq Vorticity in the differential equations for conservation od mass, momentum and energy. The effect of the material, geometry and Rayleigh number on the heat transfer was investigated considering a regime which is approximately permanent.

Bilgen and Oztop (2005) conducted a natural convective heat transfer study in an inclined square cavity with isolated walls, being that one is partially opened. The flow is laminar and permanent with the Rayleigh number and the inclination angle varying from $10^{3}$ to $10^{6}$ and from $0^{\circ}$ to $120^{\circ}$, respectively.

Nasr et al. (2006) proposed a case similar to the present work where one of the vertical walls of the two-dimensional model is heated in a small portion at a constant temperature. They considered a generic system of cooling and heating with a permanent laminar convective air flow inside a cavity. It is observed that convective flow is strongly affected by the geometry.

Bakkas et al. (2006) investigated the permanent laminar natural convective flow in a two-dimensional horizontal channel with rectangular blocks mounted along the bottom surface. These blocks were heated at a constant temperature and connected to the bottom surface by layers which were adiabatically isolated. Having Rayleigh number from $10^{2}$ to $10^{6}$ and Prandtl number equal to 0.7 (air), it was verified that the block dimensions affected significantly the temperature and velocity convective fields.

Ben-Nakhi and Chamkha (2007) focused their work on the numerical study of steady, laminar, conjugate natural convection around a finned pipe placed in the center of a square enclosure with uniform internal heat generation. Four perpendicular thin fins of arbitrary and equal dimensions are attached to the pipe whose internal surface is isothermally cooled. The sides of the enclosure are considered to have finite and equal thicknesses and their external sides are isothermally heated. The problem is put into dimensionless formulation and solved numerically by means of the finite-volume method. Representative results illustrating the effects of the finned pipe inclination angle and fins length on the streamlines and temperature contours within the enclosure are reported. In addition, results for the local and average Nusselt numbers are presented and discussed for various parametric conditions.

The study of natural convection in a threedimensional domain is still not quite explored in literature where works such Janssen et al. (1993) and Tric et al. (2000) can be found.

Janssen et al. (1993) carried out a study of natural convection in a cubic cavity using the Finite Volume Method with permanent and transient flows. In the permanent flow case, the boundary layer along the wall was studied while in the transient regime, the convective flow periodicity generated by a $3 \mathrm{D}$ model was investigated. A comparison with the classic 2D model was conducted.

Tric et al. (2000) studied exact solutions to the governing equations of natural convection of air inside cubic cavities which were thermally loaded by two opposite vertical walls with different temperatures and Rayleigh numbers going up to $10^{7}$. The solutions were considered exact with relative global errors below $0.03 \%$ and $0.05 \%$ for Rayleigh numbers $10^{3}$ and $10^{7}$, respectively.

In the present work, permanent and laminar natural convection study in a cubic cavity with fourfinned aluminum dissipator placed on a bottom horizontal surface is carried out. Heat transfer is investigated based on temperature and velocity behaviour and on the local Nusselt number along the bottom heated surface of the base of the dissipater in contact with the bottom surface of the cavity. The remaining part of the bottom surface of the cavity is 
thermally isolated. The lateral vertical walls are kept with an uniform low temperature and the cavity upper horizontal wall is thermally isolated. Figure 1 shows details of the geometry. The solution to this problem is found by the application of the Fluid Dynamics Calculus using the Finite Volume Method and the Eulerian scheme to discretize the domain in space and time. This is done by integrating the transport differential equations of mass, momentum and energy. The mesh has 36,194 nodes and 174,909 elements where 160,281 are tetrahedral and 14,312 are prismatic which are placed near the lateral vertical walls in order to capture the boundary layer effects. This mesh is used in all cases. Two cases are analyzed with Rayleigh numbers $10^{6}$ and $10^{7}$. Temperature and velocity distributions are analyzed over a vertical section that crosses the half part of the base and fins. The Nusselt number is also calculated along the base by ranging the Rayleigh number. The machine used to run all cases has a processor Intel Pentium $4^{\circledR}$ that runs at $3.0 \mathrm{GHz}$ and $2 \mathrm{~GB}$ of RAM. The time computing cost was approximately 49 minutes for Rayleigh number of $10^{6}$ and $10^{7}$, for physical time of $4 \mathrm{~s}$. CFD software package from ANSYS CFX $-5.6^{\circledR}$ was used.

\section{PROBLEM DESCRIPTION}

Figure $1 \mathrm{a}$ and $1 \mathrm{~b}$ show the geometry with domain $\Omega$ that is filled with air $(\operatorname{Pr}=0.7)$ and whose base with fins made of aluminum. It is considered a cubic cavity where $S_{1}$ and $S_{2}$ are the isolated surfaces. $\mathrm{S}_{3}$ and $\mathrm{S}_{6}$ are surfaces that are kept at an uniform low temperature while $\mathrm{S}_{7}$ is at an uniform high temperature. The local heating is simulated by a heat source that is located in the middle portion of the base wall, $\mathrm{S}_{7}$.

The initial condition on the entire domain $\Omega$ is taken for temperature $\theta=0$ and air velocities $\mathrm{u}=\mathrm{v}=$ $\mathrm{w}=0$. All properties are considered constant, except the density on the buoyancy forces that follows the Boussinesq approximation.

Figure $2 \mathrm{a}$ and $2 \mathrm{~b}$ depict the mesh used in the computational simulation, projected over $\mathrm{YZ}$ plan, and the solid body mesh.

\section{Problem hypotheses}

The following hypotheses are considered:

a) Three-dimensional domain;

b) Unsteady regime;

c) Laminar and incompressible flow;

d) Viscous dissipation is neglected;

e) Physical properties $\left(\rho, \mu, c_{p}, k\right)$ are constant, except density in the buoyancy forces;

f) No internal heat generation.

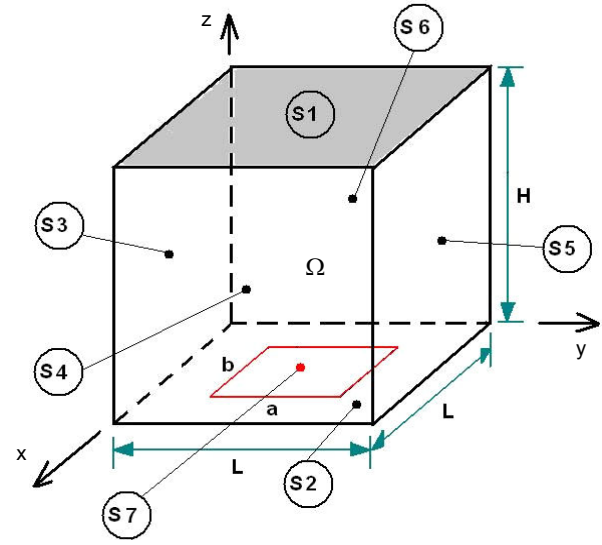

Figure 1a. Computational domain: geometry in 3D.

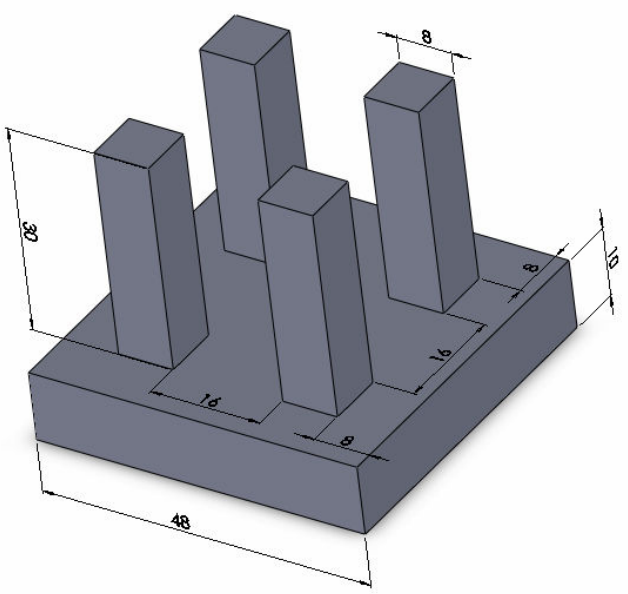

Figure 1b. Computational domain: dissipator mounted on $\mathrm{S}_{7}$ surface, with four 4 rectangular fins (dimensions in $\mathrm{mm}$ ).

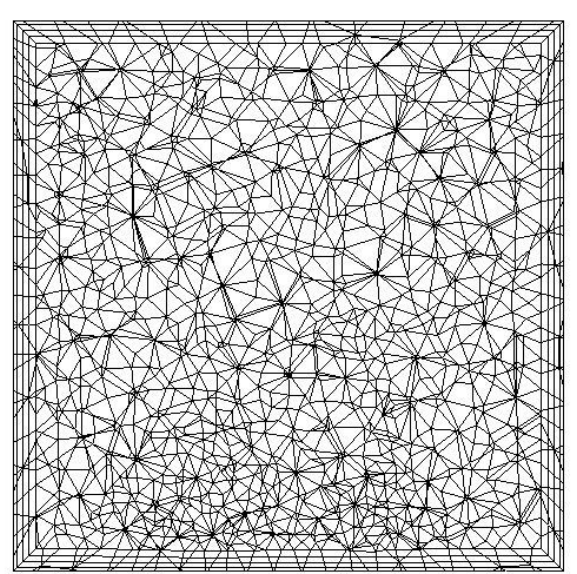

Figure 2a. Computational mesh: in a vertical surface, $\mathrm{YZ}$ plan for $\mathrm{x}=0.04 \mathrm{~m}$, with prismatic (boundary layer) and tetrahedral elements. 


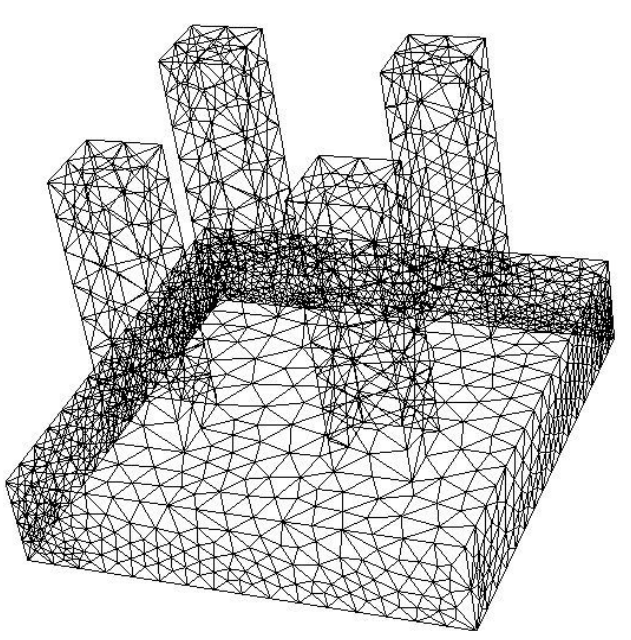

Figure 2b. Computational mesh: in the aluminum dissipator.

\section{Governing equations}

With the above considerations, the conservation equations for air can be written as follows:

i) Continuity:

$\frac{\partial \mathrm{u}}{\partial \mathrm{x}}+\frac{\partial \mathrm{v}}{\partial \mathrm{y}}+\frac{\partial \mathrm{w}}{\partial \mathrm{z}}=0$

ii) Momentum:

$\rho\left(\frac{\partial u}{\partial t}+u \frac{\partial u}{\partial x}+v \frac{\partial u}{\partial y}+w \frac{\partial u}{\partial z}\right)=-\frac{\partial p}{\partial x}$

$+\mu\left(\frac{\partial^{2} u}{\partial x^{2}}+\frac{\partial^{2} u}{\partial y^{2}}+\frac{\partial^{2} u}{\partial z^{2}}\right)$

$\rho\left(\frac{\partial v}{\partial t}+u \frac{\partial v}{\partial x}+v \frac{\partial v}{\partial y}+w \frac{\partial v}{\partial z}\right)=-\frac{\partial p}{\partial y}$

$+\mu\left(\frac{\partial^{2} v}{\partial x^{2}}+\frac{\partial^{2} v}{\partial y^{2}}+\frac{\partial^{2} v}{\partial z^{2}}\right)$

$\rho\left(\frac{\partial w}{\partial t}+u \frac{\partial w}{\partial x}+v \frac{\partial w}{\partial y}+w \frac{\partial w}{\partial z}\right)=-\frac{\partial p}{\partial z}$

$+\mu\left(\frac{\partial^{2} \mathrm{w}}{\partial \mathrm{x}^{2}}+\frac{\partial^{2} \mathrm{w}}{\partial \mathrm{y}^{2}}+\frac{\partial^{2} \mathrm{w}}{\partial \mathrm{z}^{2}}\right)+\rho g \beta\left(\mathrm{T}-\mathrm{T}_{0}\right)$

iii) Energy:

$\frac{\partial \mathrm{T}_{\mathrm{f}}}{\partial \mathrm{t}}+\mathrm{u} \frac{\partial \mathrm{T}_{\mathrm{f}}}{\partial \mathrm{x}}+\mathrm{v} \frac{\partial \mathrm{T}_{\mathrm{f}}}{\partial \mathrm{y}}+\mathrm{w} \frac{\partial \mathrm{T}_{\mathrm{f}}}{\partial \mathrm{z}}$
$=\frac{\mathrm{k}_{\mathrm{f}}}{\rho_{\mathrm{f}} \mathrm{c}_{\mathrm{pf}}}\left(\frac{\partial^{2} \mathrm{~T}_{\mathrm{f}}}{\partial \mathrm{x}^{2}}+\frac{\partial^{2} \mathrm{~T}_{\mathrm{f}}}{\partial \mathrm{y}^{2}}+\frac{\partial^{2} \mathrm{~T}_{\mathrm{f}}}{\partial \mathrm{z}^{2}}\right)$ where $\mathrm{u}, \mathrm{v}$, and $\mathrm{w}$ are the flow velocity components in $\mathrm{m} / \mathrm{s}, \mathrm{x}, \mathrm{y}$ and $\mathrm{z}$ are the directions in space, $\mathrm{t}$ is the time in $\mathrm{s}, \rho$ is the fluid density in $\mathrm{kg} / \mathrm{m}^{3} ; \mathrm{p}$ is the flow relative pressure in $\mathrm{Pa}, \mathrm{g}$ is the local acceleration component in $\mathrm{m} / \mathrm{s}^{2}$, and $\beta$ is the volumetric coefficient of thermal expansion in $\mathrm{K}^{-1}$. The subscript f represents fluid (air).

The conservation equation for the aluminum domain can be written as:

$\frac{\partial \mathrm{T}_{\mathrm{s}}}{\partial \mathrm{t}}=\frac{\mathrm{k}_{\mathrm{s}}}{\rho_{\mathrm{s}} \mathrm{c}_{\mathrm{ps}}}\left(\frac{\partial^{2} \mathrm{~T}_{\mathrm{s}}}{\partial \mathrm{x}^{2}}+\frac{\partial^{2} \mathrm{~T}_{\mathrm{s}}}{\partial \mathrm{y}^{2}}+\frac{\partial^{2} \mathrm{~T}_{\mathrm{s}}}{\partial \mathrm{z}^{2}}\right)$

where the subscript s stands for solid (aluminum).

\section{Boundary and initial conditions}

They are as follows:

i) Initial Conditions:

for $\mathrm{t}=0$ :

$\mathrm{u}=\mathrm{v}=\mathrm{w}=0 \quad($ in $\Omega)$

$\mathrm{T}=\mathrm{T}_{0}=\frac{\mathrm{T}_{\mathrm{c}}+\mathrm{T}_{\mathrm{h}}}{2} \quad($ in $\Omega)$

ii) Boundary Conditions:

for $\mathrm{t}>0$ :

$$
\begin{array}{ll}
\mathrm{T}=\mathrm{T}_{\mathrm{h}} & \left(\text { on } \mathrm{S}_{7}\right) \\
\mathrm{T}=\mathrm{T}_{\mathrm{c}} & \left(\text { on } \mathrm{S}_{3} \text { to } \mathrm{S}_{6}\right) \\
\mathrm{q}=\frac{\partial \mathrm{T}}{\partial \mathrm{n}}=0 & \left(\text { on } \mathrm{S}_{1} \text { and } \mathrm{S}_{2}\right) \\
\mathrm{u}_{\mathrm{w}}=\mathrm{v}_{\mathrm{w}}=\mathrm{w}_{\mathrm{w}}=0 & \left(\text { on } \mathrm{S}_{1}, \ldots, \mathrm{S}_{7}\right)
\end{array}
$$

where $\mathrm{S}_{1}, \mathrm{~S}_{2}, \mathrm{~S}_{3}, \mathrm{~S}_{4}, \mathrm{~S}_{5}, \mathrm{~S}_{6}$, and $\mathrm{S}_{7}$ represent the surfaces on the boundaries of the domain $\Omega$, as shown in Fig. 1.

\section{Dimensionless equations}

In order to generalize the theorical analysis governed by equations 1 to 6 , dimensionless variables are introduced:

$$
\begin{aligned}
& \tau=\frac{v t}{H^{2}}, X=\frac{x}{H}, Y=\frac{y}{H}, \\
& Z=\frac{Z}{H} U=\frac{u H}{v} \\
& V=\frac{v H}{v}, W=\frac{w H}{v},
\end{aligned}
$$


$\mathrm{P}=\frac{p H^{2}}{\rho v^{2}}, \theta=\frac{\mathrm{T}-\mathrm{T}_{\mathrm{o}}}{\mathrm{T}_{\mathrm{h}}-\mathrm{T}_{\mathrm{o}}}$

where $\tau$ is the dimensionless time; $\mathrm{X}, \mathrm{Y}$ e $\mathrm{Z}$ are the dimensionless coordinates; $\mathrm{U}, \mathrm{V}, \mathrm{W}$ are the dimensionless velocity components; $\mathrm{P}$ is the relative dimensionless pressure, and $\theta$ is the dimensionless temperature.

Substituting (13) and (14) in (1) to (5):

$\frac{\partial \mathrm{U}}{\partial \mathrm{X}}+\frac{\partial \mathrm{V}}{\partial \mathrm{Y}}+\frac{\partial \mathrm{W}}{\partial \mathrm{Z}}=0$

$\frac{\partial \mathrm{U}}{\partial \tau}+\mathrm{U} \frac{\partial \mathrm{U}}{\partial \mathrm{X}}+\mathrm{V} \frac{\partial \mathrm{U}}{\partial \mathrm{Y}}+\mathrm{W} \frac{\partial \mathrm{U}}{\partial \mathrm{Z}}=-\frac{\partial \mathrm{P}}{\partial \mathrm{X}}$

$+\left(\frac{\partial^{2} \mathrm{U}}{\partial \mathrm{X}^{2}}+\frac{\partial^{2} \mathrm{U}}{\partial \mathrm{Y}^{2}}+\frac{\partial^{2} \mathrm{U}}{\partial \mathrm{Z}^{2}}\right)$

$\frac{\partial \mathrm{V}}{\partial \tau}+\mathrm{U} \frac{\partial \mathrm{V}}{\partial \mathrm{X}}+\mathrm{V} \frac{\partial \mathrm{V}}{\partial \mathrm{Y}}+\mathrm{W} \frac{\partial \mathrm{V}}{\partial \mathrm{Z}}=-\frac{\partial \mathrm{P}}{\partial \mathrm{Y}}$

$+\left(\frac{\partial^{2} \mathrm{~V}}{\partial \mathrm{X}^{2}}+\frac{\partial^{2} \mathrm{~V}}{\partial \mathrm{Y}^{2}}+\frac{\partial^{2} \mathrm{~V}}{\partial \mathrm{Z}^{2}}\right)$

$\frac{\partial \mathrm{W}}{\partial \tau}+\mathrm{U} \frac{\partial \mathrm{W}}{\partial \mathrm{X}}+\mathrm{V} \frac{\partial \mathrm{W}}{\partial \mathrm{Y}}+\mathrm{W} \frac{\partial \mathrm{W}}{\partial \mathrm{Z}}=-\frac{\partial \mathrm{P}}{\partial \mathrm{Z}}$

$+\left(\frac{\partial^{2} \mathrm{~W}}{\partial \mathrm{X}^{2}}+\frac{\partial^{2} \mathrm{~W}}{\partial \mathrm{Y}^{2}}+\frac{\partial^{2} \mathrm{~W}}{\partial \mathrm{Z}^{2}}\right)+\frac{\mathrm{Gr}}{2} \frac{\partial \theta}{\partial \mathrm{X}}$

$\frac{\partial \theta_{\mathrm{f}}}{\partial \tau}+\mathrm{u} \frac{\partial \theta_{\mathrm{f}}}{\partial \mathrm{X}}+\mathrm{v} \frac{\partial \theta_{\mathrm{f}}}{\partial \mathrm{Y}}+\mathrm{w} \frac{\partial \theta_{\mathrm{f}}}{\partial \mathrm{Z}}$

$=\frac{1}{\operatorname{Pr}}\left(\frac{\partial^{2} \theta_{\mathrm{f}}}{\partial \mathrm{X}^{2}}+\frac{\partial^{2} \theta_{\mathrm{f}}}{\partial \mathrm{Y}^{2}}+\frac{\partial^{2} \theta_{\mathrm{f}}}{\partial \mathrm{Z}^{2}}\right)$

For the solid domain:

$\frac{\partial \theta_{\mathrm{s}}}{\partial \tau}=\frac{1}{\operatorname{Pr}}\left(\frac{\partial^{2} \theta_{\mathrm{s}}}{\partial \mathrm{X}^{2}}+\frac{\partial^{2} \theta_{\mathrm{s}}}{\partial \mathrm{Y}^{2}}+\frac{\partial^{2} \theta_{\mathrm{s}}}{\partial \mathrm{Z}^{2}}\right)$

where Gr and Pr are the Grashof and Prandtl numbers defined respectively by the following:

$\mathrm{Gr}=\frac{\mathrm{g} \beta\left(\mathrm{T}_{\mathrm{h}}-\mathrm{T}_{\mathrm{c}}\right) \mathrm{H}^{3}}{v^{2}}$

$\operatorname{Pr}=\frac{v}{\alpha}=\frac{\mu c_{p}}{K}=\frac{\rho v c_{p}}{K}$

In order to calculate the local Nusselt number, Fig. 3 presents the energy balance along the dissipator surface. One can say that the heat received $\left(\mathrm{Q}_{\mathrm{w}}\right)$ is equal to the heat delivered $\left(\mathrm{Q}_{\mathrm{fi}}\right)$ taking the aluminum part as the control volume.

So:
$\mathrm{Q}_{\mathrm{w}}=\mathrm{Q}_{\mathrm{fi}}$

And then:

$\mathrm{q}_{\mathrm{w}} \mathrm{A}_{\mathrm{w}}=\left.\mathrm{k}_{\mathrm{s}} \frac{\partial \mathrm{T}}{\partial \mathrm{z}}\right|_{\mathrm{s}} \cdot \mathrm{A}_{\mathrm{w}}=\mathrm{hA_{ \textrm {fi } }}\left(\mathrm{T}_{\mathrm{h}}-\mathrm{T}_{\mathrm{c}}\right)$

where $\mathrm{q}_{\mathrm{w}}$ and $\mathrm{q}_{\mathrm{fi}}$ are the heat fluxes on $\mathrm{S}_{7}$ and the dissipater surface, respectively.

Since:

$\left.\frac{\partial \mathrm{T}}{\partial \mathrm{z}}\right|_{\mathrm{s}}=-\frac{\left[\mathrm{T}_{\mathrm{h}}-\mathrm{T}(\delta)\right]}{\delta}$

and,

$\mathrm{Nu}_{\mathrm{L}}=\frac{\mathrm{h} \mathrm{H}^{*}}{\mathrm{k}_{\mathrm{f}}}$

The average Nusselt number $\mathrm{Nu}$ is calculated by the expression as follows:

$\mathrm{Nu}=\frac{\mathrm{A}_{\mathrm{w}} \mathrm{k}_{\mathrm{s}} \mathrm{H}^{*}}{\mathrm{~A}_{\mathrm{fi}} \mathrm{k}_{\mathrm{f}} \delta}\left\{\frac{\left[\mathrm{T}_{\mathrm{h}}-\mathrm{T}(\delta)\right]}{\left(\mathrm{T}_{\mathrm{h}}-\mathrm{T}_{\mathrm{c}}\right)}\right\}$

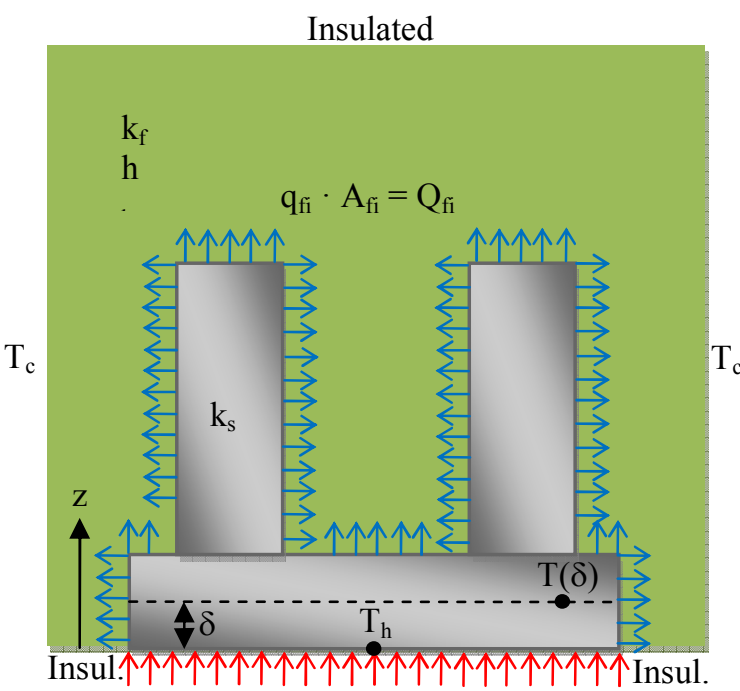

$\mathrm{q}_{\mathrm{w}} \cdot \mathrm{A}_{\mathrm{w}}=\mathrm{Q}_{\mathrm{w}}$

Figure 3. Heat transfer balance along the dissipater surface.

where $k_{f}$ and $k_{s}$ are the fluid and solid thermal conductivity, $\mathrm{h}$ is the local convective heat transfer coefficient, $\delta$ is a small distance from the dissipater bottom $(\delta / H=0.025), A_{w}$ and $A_{f i}$ are the $S_{7}$ and the aluminum surfaces in contact with air, respectively, and $\mathrm{H}^{*}$ is any relevant measure to obtain appropriate $\mathrm{Nu}$ value orders. 
The initial and boundary conditions are now expressed in the dimensionless form as:

i) Initial conditions:

for $\tau=0$ :

$\mathrm{U}=\mathrm{V}=\mathrm{W}=0$

( in $\Omega$ )

$\theta=\theta_{0}=\frac{1}{2}$

ii) Boundary conditions:

for $\tau>0$ :

$$
\begin{array}{ll}
\theta=1 & \left(\text { on } \mathrm{S}_{7}\right) \\
\theta=-1 & \left(\text { on } \mathrm{S}_{3}, \ldots, \mathrm{S}_{6}\right) \\
\mathrm{Q}=-\frac{\partial \theta}{\partial \mathrm{N}}=0 & \left(\text { on } \mathrm{S}_{1} \text { and } \mathrm{S}_{2}\right) \\
\mathrm{U}_{\mathrm{w}}=\mathrm{V}_{\mathrm{w}}=\mathrm{W}_{\mathrm{w}}=0 & \left(\text { on } \mathrm{S}_{1}, \ldots, \mathrm{S}_{7}\right)
\end{array}
$$

\section{NUMERICAL METHOD}

The solution of the partial differential equations in time and space can be solved using the Computational Fluid Dynamics (CFD) by Finite Volume Method (FVM), which is a method of discretization in space and in time of the entire domain, which can use a mesh with finite number of volumes (Barth and Ohlberger, 2004).

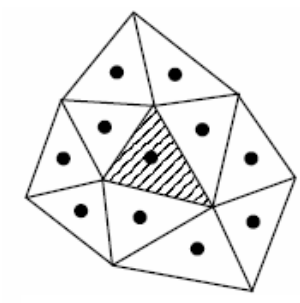

Centralized face

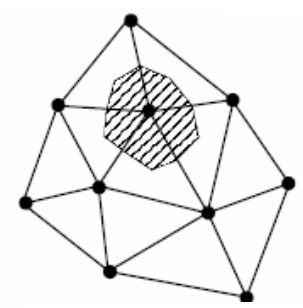

- Point of calculation

Control volume

Centralized volume

Figure 4. Details of the control volume used in the Finite Volume Method (Barth and Ohlberger, 2004).

In this method of discretization, the mesh can have two typical volume schemes: centralized face and centralized volume. For both schemes of control volume, the variables can be solved in terms of average values. Figure 4 shows the centered face and control volume used in the Finite Volume Method, as in Barth and Ohlberger (2004).

The governing equations can be solved applying a suitable algorithm (Euler's equations for inviscid flows and Navier-Stokes's equations for viscous flow). In particular case of phenomena with fluid flows and heat transfer, it is necessary to link the pressure and velocity. Among the algorithms that can solve all variables in the same time step with velocity and pressure linked equation, CFD has used the SIMPLE method (Shaw, 1992).

This methodology is an interactive process, where the error or residual is compared to a reference error, also named "target error". In this way, flow and heat transfer simulations require the introduction of suitable flow and heat transfer models to guarantee a satisfactory convergence.

\section{RESULT ANALYSIS}

Through the iterative calculation using CFD, it was observed the convergence in relation to the deviation calculated by the goal error equal to $10^{6}$ for the two cases where $\mathrm{Ra}=10^{6}$ and $10^{7}$. Figure 5 shows the Convergence Curves for the local Nusselt number on $\mathrm{S}_{2}$ and $\mathrm{S}_{7}$ for $\mathrm{Ra}=10^{6}$ and $10^{7}$.

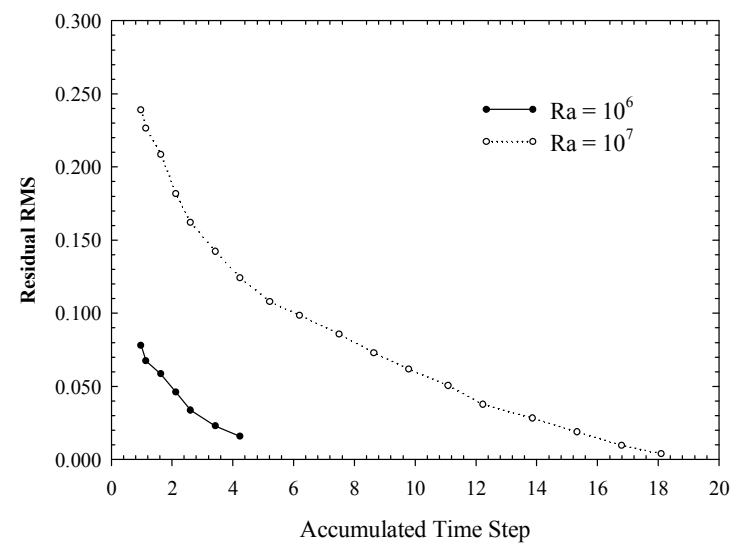

Figure 5. Convergence curves for the RMS deviation on heat transfer rate for $\mathrm{Ra}=10^{6}$ and $10^{7}$.

It can be noticed that convergence is rapidly reached for lower Rayleigh numbers where the internal flow is significantly laminar and the viscosity effects are stronger.

Table 1 shows the results for the average Nusselt number given by Eq. (26) at $\delta=0.003$ with $\mathrm{H}$ $=0.05 \mathrm{~m}$, where $\mathrm{H}$ is the height of dissipator placed on the bottom surface. It can be observed that $\mathrm{Nu}$ increase as Rayleigh number goes up to $10^{7}$, due to the higher temperature gradient between the surfaces $\mathrm{S}_{7}$ and $\mathrm{S}_{8}$.

To observe the effect of Rayleigh number on heat transfer in the cubic cavity, Figs. 6 and 7 depict the temperature and velocity vectors distributions 
plotted on the ZX plan at $(\mathrm{x} / \mathrm{L}=0.40 ; 0 \leq \mathrm{y} / \mathrm{L} \leq 1$, $0 \leq \mathrm{z} / \mathrm{H} \leq 1)$.

From Figs. 6(a) and 7(a), it is noted that the ascending convective flow increases with Rayleigh number increase. For $\mathrm{Ra}=10^{6}$, two opposite vortices of the same intensity are formed on the reference plan at $\mathrm{x} / \mathrm{L}=0.40 ; 0 \leq \mathrm{y} / \mathrm{L} \leq 1,0 \leq \mathrm{z} / \mathrm{H} \leq 1$, progressively nearer the finned surface.

Table 1. Average Nusselt number for $\mathrm{Ra}=10^{6}$ and $10^{7}$ at the last time instant.

\begin{tabular}{|c|c|c|}
\hline & $\mathrm{Ra}=10^{6}$ & $\mathrm{Ra}=10^{7}$ \\
\hline $\mathrm{A}_{\mathrm{w}}\left[\mathrm{m}^{2}\right]$ in $\mathrm{S}_{7}$ & $2.30 \mathrm{E}-03$ & $2.30 \mathrm{E}-03$ \\
\hline$A_{c}\left[m^{2}\right]$ in $S_{8}$ & $8.06 \mathrm{E}-03$ & $8.06 \mathrm{E}-03$ \\
\hline $\mathrm{k}_{\mathrm{s}}(\mathrm{Al})\left[\mathrm{W} \mathrm{m} \mathrm{m}^{\wedge}-1 \mathrm{~K}^{\wedge}-1\right]$ & 237.0 & 237.0 \\
\hline $\mathrm{k}_{\mathrm{f}}($ air $)\left[\mathrm{W} \mathrm{m}^{\wedge}-1 \mathrm{~K}^{\wedge}-1\right]$ & 0.026100 & 0.026100 \\
\hline $\mathrm{H}[\mathrm{m}]$ & 0.12 & 0.12 \\
\hline$\delta_{\mathrm{i}}[\mathrm{m}]$ & 0.003 & 0.003 \\
\hline $\mathrm{T}_{\mathrm{h}}[\mathrm{K}]$ & 673.2 & 673.2 \\
\hline $\mathrm{T}_{\mathrm{c}}[\mathrm{K}]$ & 667.1 & 618.1 \\
\hline $\mathrm{T}\left(\delta_{\mathrm{i}}\right)[\mathrm{K}]$ & 673.1 & 654.1 \\
\hline $\mathrm{Nu}$ & 518.8 & 35874.9 \\
\hline
\end{tabular}

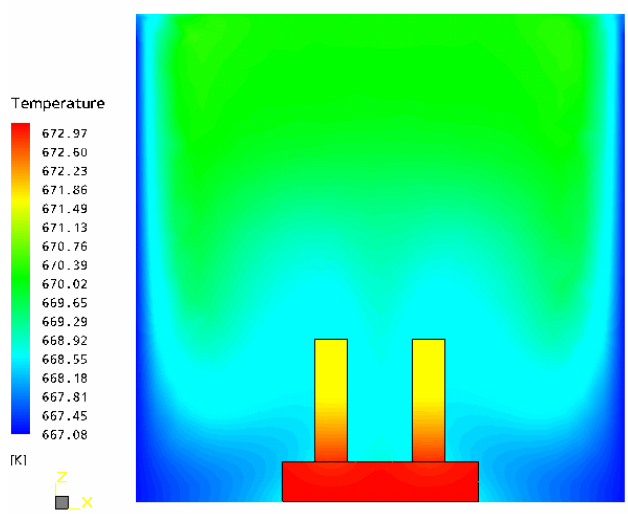

Figure 6a. Case $1-\mathrm{Ra}=10^{6}$ at the final instant for contour number 100: temperature distribution, plan ZX.

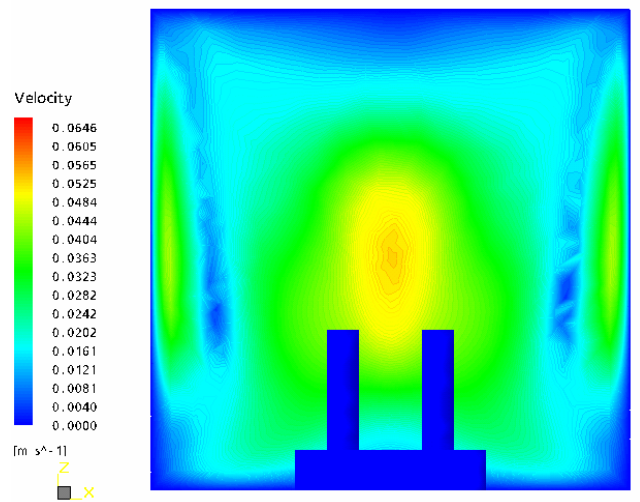

Figure $6 \mathrm{~b}$. Case $1-\mathrm{Ra}=10^{6}$ at the final instant for contour number 100: velocity vector field at $=0.012$ $\mathrm{m}$, plan ZX.



Figure 7a. Case $2-\mathrm{Ra}=10^{7}$ at the final instant for contour number 100: temperature distribution, plan ZX.

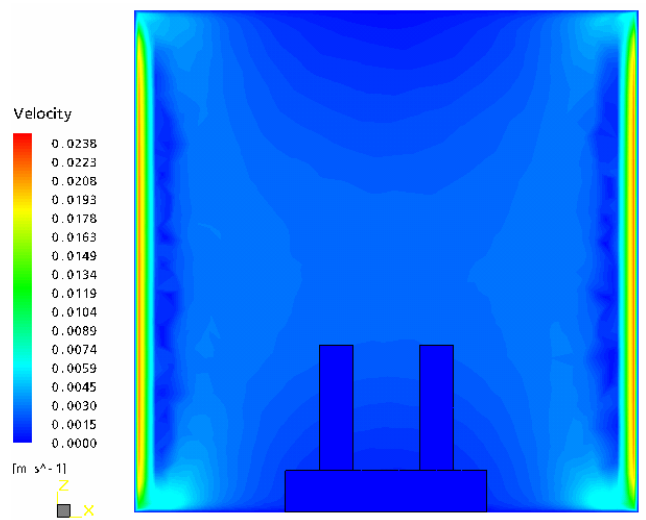

Figure $7 \mathrm{~b}$. Case $2-\mathrm{Ra}=10^{7}$ at the final instant for contour number 100: velocity vector field at $=0.012$ $\mathrm{m}$, plan ZX.

For $\mathrm{Ra}=10^{6}$ and $10^{7}$, a typical behavior takes place. This behavior represents the strength order of the ascending convective flow between the fin heated surface and the upper isolated horizontal surface. This can also be seen in Figs 6(b) and 7(b), where the progressive increase of the maximum velocity vector is noted when Rayleigh number is higher.

One can also note that in Figs. 6(a) and 6(b), the isotherms find themselves in a more uniform distribution and deformed for $\mathrm{Ra}=10^{6}$, along the fin and in the fluid domain, thus enhancing the heat transfer. For $\mathrm{Ra}=10^{7}$, the heat transfer is predominantly featured by conductive effect, as depicted in Figs. 7(a) and 7(b). Significantly, for Figs 6 and 7, the calculus indicates that the temperature gradient becomes stronger near the fin region as $\mathrm{Ra}$ increases.

An analysis in other flow plans is strongly recommended to analyze the intensity of the vortices generated in the third dimension. According to Bilgen and Oztop (2005) and Nasr et al. (2006), the temperature distributions as well as the vortices intensities are affected by the secondary effects of the ascending convective flow given by the third 
dimension of the cavity. This phenomenon implies the importance of the 3D study, as suggested by Janssen et al. (1993).

\section{CONCLUSIONS}

The natural convection study in a cubic cavity using CFD showed that:

a) The average Nusselt number on the cavity base increased with the Rayleigh number increase due to the fact that the temperature gradient was higher between the heated surface and the temperature of the fluid domain;

b) The ascending convective flow penetration from the heated surface was stronger as Ra increased;

c) It was observed a progressive formation of vortices with a plume shape from the finned surface for $\mathrm{Ra}=10^{6}$. These vortices had equal intensity and opposite directions.

d) The progressive increase of the flow maximum velocity vector induced by convection was verified with the Rayleigh number increase up to $10^{7}$.

In this way, with a satisfactory precision, the fluid dynamics calculus applied in this work is revealed to be a promising natural convection study applied to the electronic components.

\section{ACKNOWLEDGEMENTS}

The authors would like to thank The National Council for Research and Development - CNPq, The Scientific Community Support Fund - CAPES, and The Research Support Foundation of the State of Minas Gerais - FAPEMIG for the financial support granted for the present work. The authors acknowledge with gratitude the technical support of the Engineering Simulation and Scientific Software ESSS, and the Excellence Center in Thermal Systems and Distributed Energy - NEST of the Federal University of Itajubá - UNIFEI to make it possible the use of the software ANSYS CFX ${ }^{\circledR}$.

\section{REFERENCES}

Bakkas, M., Amahmid, A., and Hasnaoui, M.,
2006, Steady natural convection in a horizontal channel containing heated rectangular blocks periodically mounted on its lower wall, Energy Conversion and Management, $\mathrm{n}^{\circ}$ 47, pp. 509-528.

Barth, T., and Ohlberger, M., 2004, Finite Volume Methods: Foundation and Analysis, Encyclopedia of Computational Mechanics, John Wiley \& Sons Ltd.

Ben-Nakhi, A., and Chamkha, A. J., 2007, Conjugate natural convection around a finned pipe in a square enclosure with internal heat generation, International Journal of Heat and Mass Transfer, $\mathrm{n}^{\circ}$ 50, pp. 2260-2271.

Bilgen, E., and Oztop, H., 2005, Natural convection heat transfer in partially open inclined square cavities, International Journal of Heat and Mass Transfer, $\mathrm{n}^{\circ} 48$, pp. 1470-1479.

Dong, S. F., and Li, Y. T., 2004, Conjugate of natural convection and conduction in a complicated enclosure, International Journal of Heat and Mass Transfer, $n^{\circ} 47$, pp. 2233-2239.

Janssen, R. J. A., Henkes, R. A. W. M., and Hoogendoorn, C. J., 1993, Transition to timeperiodicity of a natural convection flow in a $3 \mathrm{D}$ differentially heated cavity, International Journal of Heat and Mass Transfer, Vol. 36, pp. 2927-2940.

Nasr, B. K., Chouikh, R., Kerkeni, C., and Guizani, A., 2006, Numerical study of the natural convection in cavity heated from the lower corner and cooled from the ceiling, Applied Thermal Engineering, $\mathrm{n}^{\circ} 26$, pp. 772-775.

Shaw, C. T., 1992, Using computational fluid dynamics - an introduction to the practical aspects of using $C F D$, Prentice Hall Publications.

Tric, E., Labrosse, G., and Betrouni, M., 2000, A first incursion into the $3 \mathrm{D}$ structure of natural convection of air in a differentially heated cubic cavity, from accurate numerical solutions, International Journal of Heat and Mass Transfer, Vol. 43, pp. 4043-4056.

\section{RESPONSIBILITY NOTICE}

The authors are the only responsible for the printed material included in this paper. 